\title{
Dating sediment burial with in situ-produced cosmogenic nuclides: theory, techniques, and limitations
}

\author{
Darryl E. Granger ${ }^{\mathrm{a}, *}$, Paul F. Muzikar ${ }^{\mathrm{b}}$ \\ a Prime Laboratory, Department of Earth and Atmospheric Sciences, Purdue University, West Lafayette, IN 47907-1397, USA \\ b Department of Physics, Purdue University, West Lafayette, IN 47907-1396, USA
}

Received 21 September 2000; received in revised form 14 March 2001; accepted 15 March 2001

\begin{abstract}
Dating sediment burial over million-year time scales is crucial in many areas of the Earth sciences and archeology, but is often difficult using traditional techniques. Sediment burial can be dated by the radioactive decay of cosmogenic nuclides, provided that the sediment was exposed to cosmic rays prior to burial. Dating calculations are straightforward if sediment is buried deeply and rapidly enough to prevent cosmogenic nuclide production after burial. However, the analysis can be complicated by postburial production if sediment is insufficiently shielded from secondary cosmic-ray nucleons and muons. This paper discusses how buried sediments can be dated over timescales up to $5 \mathrm{Myr}$ using ${ }^{26} \mathrm{Al}$ and ${ }^{10} \mathrm{Be}$ in quartz. (C) 2001 Published by Elsevier Science B.V.
\end{abstract}

Keywords: cosmogenic elements; geochronology; burial; sediments

\section{Introduction}

Dating sediment deposition over million-year timescales is important in many areas of geology, geomorphology, and paleoanthropology. Fluvial sediments reveal the pace of landscape evolution, and can be used to determine how quickly basins fill and rivers incise in response to active tectonics or climate change. Dating fossil-bearing sediments is crucial for deciphering the pattern of biological evolution, in particular hominid evolution, over

\footnotetext{
* Corresponding author. Tel.: +1-765-494-0043;

Fax: +1-765-494-1210; E-mail: dgranger@purdue.edu
}

the past several million years. Yet continental sediments are often difficult to date over these timescales in the absence of volcanic or biostratigraphic markers. In this paper we present a discussion of recently developed techniques for dating buried sediment that are based on the radioactive decay of cosmogenic nuclides.

Cosmogenic radionuclides such as ${ }^{26} \mathrm{Al}$ and ${ }^{10} \mathrm{Be}$ are produced, in both the atmosphere and within minerals near the Earth's surface, by nuclear reactions initiated by cosmic-ray particles [1]. Although the nuclides are produced in very small quantities in rocks, the development of accelerator mass spectrometry (AMS) techniques over the past $20 \mathrm{yr}$ has made their measurement routine at levels as low as $10^{6}$ atoms (see [2]).

Dating materials by radioactive decay of cosmogenic nuclides requires first that radionuclides 
be produced within the sample, and second that the sample has subsequently been shielded from cosmic radiation. In this paper we will focus on ${ }^{26} \mathrm{Al}$ and ${ }^{10} \mathrm{Be}$ produced in situ within quartz. The relatively long half-lives of these two nuclides make them useful for dating materials that were deposited over the past five million years.

${ }^{26} \mathrm{Al}$ and ${ }^{10} \mathrm{Be}$ are particularly useful for burial dating because the ratio of their production rates within mineral grains is well known and roughly independent of factors such as latitude, altitude, depth below the surface, and time [3,4]. As we will discuss in detail later in this paper, the ${ }^{26} \mathrm{Al} /{ }^{10} \mathrm{Be}$ ratio can therefore be used to date sediment burial while minimizing the confounding issues of production rate variations through time and space [5-7].

The burial dating technique was proposed by Lal and Arnold [5] and later elaborated by Lal [7]. Klein et al. [6] were the first to use the ${ }^{26} \mathrm{Al} /$ ${ }^{10} \mathrm{Be}$ pair experimentally, showing that clasts of Libyan desert glass had spent part of their histories buried within migrating sand dunes. Several other researchers have used the ${ }^{26} \mathrm{Al} /{ }^{10} \mathrm{Be}$ pair to test for burial, but not to date a burial event. For example, Nishiizumi et al. [3] showed that quartz beneath the 0.76 Myr Bishop Tuff had depressed ${ }^{26} \mathrm{Al} /{ }^{10} \mathrm{Be}$ ratios, though the data were difficult to interpret in detail. Bierman et al. [8] measured low ${ }^{26} \mathrm{Al} /{ }^{10} \mathrm{Be}$ ratios in glacially carved bedrock, and attributed this to potentially repeated episodes of burial and exhumation beneath glacial till, snow or ice. Granger et al. [9] were the first to use the ${ }^{26} \mathrm{~A} 1 /{ }^{10} \mathrm{Be}$ ratio to explicitly date sediment burial; they determined river incision rates by dating alluvial gravels that were washed into caves over the past 1.5 Myr. More recently, Granger and Smith [10] have dated 1.5 Myr alluvial deposits in Kentucky, USA, by measuring concentrations of ${ }^{26} \mathrm{Al}$ and ${ }^{10} \mathrm{Be}$ over a $10 \mathrm{~m}$ deep profile. Granger et al. [11] used ${ }^{26} \mathrm{Al} /{ }^{10} \mathrm{Be}$ ratios in sediments deposited in Mammoth Cave, KY, USA to infer the incision history of the nearby Green River over the past 3.5 Myr. These recent examples illustrate the wide applicability of burial dating, both in deeply buried cave sediments and in sedimentary deposits that may be less than $10 \mathrm{~m}$ deep.

Burial dating is in some respects similar to a different technique called surface exposure dating, in that both rely on the in situ production of cosmogenic nuclides. It is crucial for both methods that in situ production decreases with depth beneath the ground surface, approaching zero at large depths. The methods differ, however, both in how they measure time intervals and in the problems that they are useful for.

In surface exposure dating (see reviews [12-15]), it is assumed that a rock which initially contains no cosmogenic nuclides is suddenly exposed to cosmic radiation. This can occur, for example, by a glacier, a river or a landslide removing many meters of rock from a landscape [16-18]. Over time, cosmogenic nuclides accumulate in the rock, and indicate how long the rock has been exposed.

Burial dating works in a fundamentally different way. It is assumed that a rock has been exposed to cosmic rays for sufficient time to acquire an inventory of various cosmogenic nuclides. The clast is then buried quickly, so that cosmogenic production effectively ceases. Burial could be achieved by sediment being washed into a cave or being covered by many meters of overburden. In contrast to surface exposure dating, burial dating requires radioactive nuclides. After production has stopped, each radionuclide will decay with the appropriate half-life. By measuring the concentrations of several (at least two) nuclides, we can determine how long the clast has been buried.

Burial dating requires at least two nuclides because there are at least two unknowns in the clast's history. First, it is not known how long the clast was exposed prior to burial. Second, it is not known how long the clast has been buried. So, a model for the preburial nuclide accumulation must be used. The proper model will depend on whether the clast was derived from a landscape eroding in steady state or not, but it will always contain at least one unknown parameter such as the exposure time. The concentrations of two different cosmogenic nuclides in the same clast provide enough information to solve for two unknowns.

There are several important points which we will consider in more detail later in this paper: 
1. Since a rock's exposure history prior to burial is not known, determining burial ages requires certain assumptions concerning its exposure to cosmic rays.

2. If the clast is not buried deeply enough, some secondary cosmic-ray particles may still penetrate the overburden and produce cosmogenic nuclides. This complicates the analysis, but an age determination is still possible.

3. The upper and lower age limits that can accurately be inferred depend upon the decay rates of the nuclides used, the precision of the AMS measurement and chemical preparation, uncertainties in cosmogenic nuclide production rates and how they vary through time, and the duration of the initial exposure.

4. In this paper, we focus most attention on burial dating using two unstable cosmogenic nuclides. As we discuss in Section 6, however, it is possible to use one stable and one unstable nuclide.

\section{In situ production of cosmogenic nuclides}

When primary cosmic-ray particles (mostly protons) strike the Earth's atmosphere, a variety of particles is produced. For the in situ production of ${ }^{26} \mathrm{Al}$ and ${ }^{10} \mathrm{Be}$ at or below the surface, two types of these secondary cosmic rays are important: nucleons (neutrons and protons) and muons. Neutrons (and some protons) produce ${ }^{26} \mathrm{Al}$ and ${ }^{10} \mathrm{Be}$ via spallation reactions in quartz, whereas muons produce these nuclides via two mechanisms. Production by slow muons comes via negative muon capture reactions, while fast muons initiate cascades of particles which can produce ${ }^{26} \mathrm{Al}$ and ${ }^{10} \mathrm{Be}$. (For specificity, we will discuss the case of ${ }^{26} \mathrm{Al}$ and ${ }^{10} \mathrm{Be}$ production in quartz, although the ideas and equations are more generally applicable.)

For quartz on the surface, the production rate due to nucleons is much larger than that due to the muons. However, muons penetrate much further than nucleons, so that at sufficient depth production by muons becomes dominant.

Production by nucleons as a function of depth can be accurately modeled by a simple exponen- tial law $[4,7]$ :

$$
P_{\mathrm{Al}, n}(z)=A_{0} \mathrm{e}^{-z / L_{0}} ; P_{\mathrm{Be}, n}(z)=B_{0} \mathrm{e}^{-z / L_{0}}
$$

where $P$ is the production rate, with subscripts $\mathrm{Al}$ and $\mathrm{Be}$ representing ${ }^{26} \mathrm{Al}$ and ${ }^{10} \mathrm{Be}$, and $n$ denotes nucleonic production; $z$ is the depth below the surface, and the nucleon decay length is given by $L_{0} \approx 160 / \rho \mathrm{cm}[19]$, where $\rho$ is the density of the overburden (in $\mathrm{g} / \mathrm{cm}^{3}$ ). Production rates at the surface depend on latitude and altitude $[1,7,20]$. Although there is not yet a consensus on their precise values, reasonable estimates, for sea level and high latitude are $A_{0} \approx 30$ and $B_{0} \approx 5$, in units of atoms per year per gram of quartz [21].

Recent work [22-25] has shown that both slow muon and fast muon components are functions of depth that are not readily modeled by simple analytic expressions. Granger and Smith [10] have shown that, for many purposes, a reasonable fit can be achieved by using the sum of three exponential terms:

$$
\begin{aligned}
& P_{\mathrm{Al}, \mu}(z)=A_{1} \mathrm{e}^{-z / L_{1}}+A_{2} \mathrm{e}^{-z / L_{2}}+A_{3} \mathrm{e}^{-z / L_{3}} \\
& P_{\mathrm{Be}, \mu}(z)=B_{1} \mathrm{e}^{-z / L_{1}}+B_{2} \mathrm{e}^{-z / L_{2}}+B_{3} \mathrm{e}^{-z / L_{3}}
\end{aligned}
$$

The first two terms in Eqs. 2 and 3 describe the production due to capture of slow negative muons. Production due to fast muons is more difficult to fit; the final terms in Eqs. 2 and 3 model this fast muon component reasonably well up to depths of about $5000 / \rho \mathrm{cm}$. The attenuation lengths are given by $L_{1} \approx 738 / \rho \mathrm{cm}$, $L_{2} \approx 2688 / \rho \mathrm{cm}$, and $L_{3} \approx 4360 / \rho \mathrm{cm}$. For typical overburden densities $\left(\rho \approx 2.6 \mathrm{~g} / \mathrm{cm}^{3}\right)$ the muon length scales are given by $L_{1} \approx 284 \mathrm{~cm}$, $L_{2} \approx 1034 \mathrm{~cm}$, and $L_{3} \approx 1677 \mathrm{~cm}$, whereas the nucleon length scale is given by $L_{0} \approx 62 \mathrm{~cm}$. The coefficients $A_{j}$ and $B_{j}$ are not yet known with good precision. Estimates for their magnitude, at sea level and high latitude and in units of atoms per year per gram of quartz are $A_{1} \approx 0.72$, $A_{2} \approx 0.16, \quad A_{3} \approx 0.19, \quad B_{1} \approx 0.09, \quad B_{2} \approx 0.02$, and $B_{3} \approx 0.02$ (for details, see [23,24]).

Though production by muons is dwarfed at the surface, for a clast buried at a depth of, say, $10 \mathrm{~m}$, 
nuclide production due to nucleons has been reduced by a factor of $10^{-7}$ from its surface value, while production from muons is still about $15 \%$ of its surface value. As we will discuss in Section 4, if sediment is buried at insufficient depth, the quantity of cosmogenic nuclides produced over millions of years of burial can dominate the decaying number of such nuclides produced prior to burial.

\section{Ideal case of burial dating}

In this section we describe how burial dating works in a simple, prototypical case, using ${ }^{26} \mathrm{Al}$ and ${ }^{10} \mathrm{Be}$ in quartz. Their mean lives are given by $\tau_{\mathrm{Al}}=1.02 \pm 0.04 \mathrm{Myr}$ [26] and $\tau_{\mathrm{Be}}=2.18 \pm 0.09$ Myr [27]. We assume that quartz is exposed to cosmic rays, and acquires certain concentrations of these two nuclides, given by $N_{\mathrm{Al}}(0)$ and $N_{\mathrm{Be}}(0)$. The quartz is then buried deeply enough so that production by cosmic rays stops; this is the key simplifying assumption of this entire section. At a time $t$ later (i.e. now) the concentrations of ${ }^{26} \mathrm{Al}$ and ${ }^{10} \mathrm{Be}$ are given by:

$N_{\mathrm{Al}}(t)=N_{\mathrm{Al}}(0) \mathrm{e}^{-t / \tau_{\mathrm{Al}}} ; N_{\mathrm{Be}}(t)=N_{\mathrm{Be}}(0) \mathrm{e}^{-t / \tau_{\mathrm{Be}}}$

The amounts of these two nuclides remaining in the quartz can be used to determine $t$, the burial age. However, since the initial amounts $N_{\mathrm{Al}}(0)$ and $N_{\mathrm{Be}}(0)$ are unknown, these equations cannot yet be solved. The solution relies on the fact that $N_{\mathrm{Al}}(0)$ and $N_{\mathrm{Be}}(0)$ are related, since the two nuclides were produced in the same piece of quartz, by the same cosmic-ray flux, over the same period of time. Thus a model must be used to describe the buildup of these nuclides prior to burial; in the rest of this section we discuss several possible models.

\subsection{Simplest buildup model}

For the simplest model, we assume that the exposure time $T$ is much shorter than either of the mean lives $\tau_{\mathrm{Al}}$ and $\tau_{\mathrm{Be}}$ and that production rates are constant during this time interval. The initial amounts are then given by the following equations:

$N_{\mathrm{Al}}(0)=P_{\mathrm{Al}} T ; N_{\mathrm{Be}}(0)=P_{\mathrm{Be}} T$

Eq. 5 for the initial concentrations can then be used in Eq. 4 to solve for the burial time $t$ :

$t=-\frac{\tau_{\mathrm{Al}} \tau_{\mathrm{Be}}}{\tau_{\mathrm{Be}}-\tau_{\mathrm{Al}}} \ln \left(\frac{P_{\mathrm{Be}} N_{\mathrm{Al}}(t)}{P_{\mathrm{Al}} N_{\mathrm{Be}}(t)}\right)$

This formula requires, besides knowledge of the two mean lives, that the production rates of ${ }^{26} \mathrm{Al}$ and ${ }^{10} \mathrm{Be}$ are known at the location of interest. One advantage of being able to use this simple buildup model is that only the ratio of the production rates is needed and this ratio is largely independent of latitude and altitude.

This prototype model can be used to illustrate the expected precision of burial dating. Let $R(t)$ be the ratio of ${ }^{26} \mathrm{Al}$ to ${ }^{10} \mathrm{Be}$. At burial this ratio starts at a value of $P_{\mathrm{Al}} / P_{\mathrm{Be}}$, and then decreases to zero with a time constant $\tau_{\text {burial }}$ given by:

$\tau_{\text {burial }}=\frac{\tau_{\mathrm{Al}} \tau_{\mathrm{Be}}}{\tau_{\mathrm{Be}}-\tau_{\mathrm{Al}}}$

(note that $\tau_{\mathrm{Be}}>\tau_{\mathrm{Al}}$ ). The characteristic time scale of this method is set by $\tau_{\text {burial }}$.

An uncertainty $\Delta R$ in measurement of the ratio $R$ translates into an uncertainty in the age $\Delta t$ given by:

$\Delta t=\tau_{\text {burial }} \frac{\Delta R}{R}$

For the ${ }^{26} \mathrm{Al}-{ }^{10} \mathrm{Be}$ case we are using as our example, $\tau_{\text {burial }}=1.92 \mathrm{Myr}$ and a $5 \%$ error in measuring $R$ results in $\Delta t=96 \mathrm{kyr}$.

Recall that Eq. 5 is based on the assumption that the buildup time, $T$, is much shorter than either mean life. It is possible to check the selfconsistency of this assumption. Once we know $t$, we can use this value to compute the values of $N_{\mathrm{Al}}(0)$ and $N_{\mathrm{Be}}(0)$. We can then use the production rates, in combination with Eq. 5 to estimate $T$ and check if our assumption is correct. Note also that we can use this simple model even if the exposure history is complicated, as long as the exposure time is short compared to the 
mean lives of the nuclides. We then interpret $P_{\mathrm{Al}}$ and $P_{\mathrm{Be}}$ as average production rates; for the age determination, only their ratio matters.

Finally, if production rates are constant, but the exposure time is not short compared to the mean lives, we may replace the approximate Eq. 5 with the complete equations:

$N_{\mathrm{Al}}(0)=P_{\mathrm{Al}} \tau_{\mathrm{Al}}\left(1-\mathrm{e}^{-T / \tau_{\mathrm{Al}}}\right)$

$N_{\mathrm{Be}}(0)=P_{\mathrm{Be}} \tau_{\mathrm{Be}}\left(1-\mathrm{e}^{-T / \tau_{\mathrm{Be}}}\right)$

Eqs. 9 and 10 may then be used in Eq. 4 to obtain two equations in the two unknowns $(T, t)$.

\subsection{Preburial concentrations for an eroding landform}

A more sophisticated (and usually more realistic) model for the preburial buildup of the cosmogenic nuclides can be constructed by assuming a landform that is eroding at rate $E$. As the landform erodes, the quartz is exhumed to the surface and then buried soon after. During the erosion process the quartz is exposed to cosmic rays; we assume that the production rate is depth-dependent, given by the following formula:

$P_{\mathrm{Al}}(z)=P_{\mathrm{Al}} \mathrm{e}^{-z / L} ; \quad P_{\mathrm{Be}}(z)=P_{\mathrm{Be}} \mathrm{e}^{-z / L}$

Here, $P_{\mathrm{Al}}$ and $P_{\mathrm{Be}}$ are production rates at the surface and $L$ is an attenuation length. These equations are a simplified version of the more complete theory presented in Section 2, with $L$ equal to $L_{0}$. We will later discuss when the use of these simplified equations is justified. If the landform has eroded at a constant rate for a long period of time, the initial concentrations of the two nuclides are given by the following expressions:

$$
\begin{aligned}
& N_{\mathrm{Al}}(0)=\frac{P_{\mathrm{Al}}}{\frac{1}{\tau_{\mathrm{Al}}}+\frac{E}{L}} \\
& N_{\mathrm{Be}}(0)=\frac{P_{\mathrm{Be}}}{\frac{1}{\tau_{\mathrm{Be}}}+\frac{E}{L}}
\end{aligned}
$$

Note that if the erosion rate is high $\left(E \tau_{\mathrm{Al}} \gg L\right)$, this model reduces to the simpler one described in Section 3.1, with the time $T$ given by $T=L / E$ [7]. In this case the ratio $R$ is independent of the erosion rate, and the burial age is not sensitive to variations in the erosion rate. To determine the burial age [9] we combine Eqs. 12 and 13 with Eq. 4 to obtain:

$$
N_{\mathrm{Al}}(t)=\frac{P_{\mathrm{Al}}}{\frac{1}{\tau_{\mathrm{Al}}}+\frac{E}{L}} \mathrm{e}^{-t / \tau_{\mathrm{Al}}}
$$

$$
N_{\mathrm{Be}}(t)=\frac{P_{\mathrm{Be}}}{\frac{1}{\tau_{\mathrm{Be}}}+\frac{E}{L}} \mathrm{e}^{-t / \tau_{\mathrm{Be}}}
$$

Eqs. 14 and 15 are a set of two equations with two unknowns ( $t$ and $E$ ). Solution of these equations yields, then, the burial age $t$ and the erosion rate $E$. This erosion rate is often referred to as the 'inherited' erosion rate, since it applies to the erosion experienced by the quartz during its accumulation of cosmogenic nuclides before its final burial.

For given data (i.e. measured values of $N_{\mathrm{Al}}(t)$ and $N_{\mathrm{Be}}(t)$ ), we may solve Eqs. 14 and 15 numerically for $t$ and $E$. In the literature, however, the solution is often presented graphically $[6,7,9]$, in a plot similar to Fig. 1. The ratio $N_{\mathrm{Al}}(t) / N_{\mathrm{Be}}(t)$ is plotted as a function of $N_{\mathrm{Be}}(t)$. We may combine Eqs. 14 and 15 to obtain the relation between these plotted quantities:

$\frac{N_{\mathrm{Al}}(t)}{N_{\mathrm{Be}}(t)}=$

$\frac{P_{\mathrm{Al}}}{P_{\mathrm{Be}}^{\tau_{\mathrm{Be}} / \tau_{\mathrm{Al}}}}\left(\frac{1}{\tau_{\mathrm{Be}}}+\frac{E}{L}\right)^{\tau_{\mathrm{Be}} / \tau_{\mathrm{Al}}}\left(\frac{1}{\tau_{\mathrm{Al}}}+\frac{E}{L}\right)^{-1}\left(N_{\mathrm{Be}}(t)\right)^{\tau_{\mathrm{Be}} / \tau_{\text {burial }}}$

For a fixed erosion rate, on a log-log plot, the ratio is a linear function of $N_{\mathrm{Be}}(t)$ with a slope of $\tau_{\mathrm{Be}} / \tau_{\text {burial }}$.

Immediately upon burial the ratio starts at the 


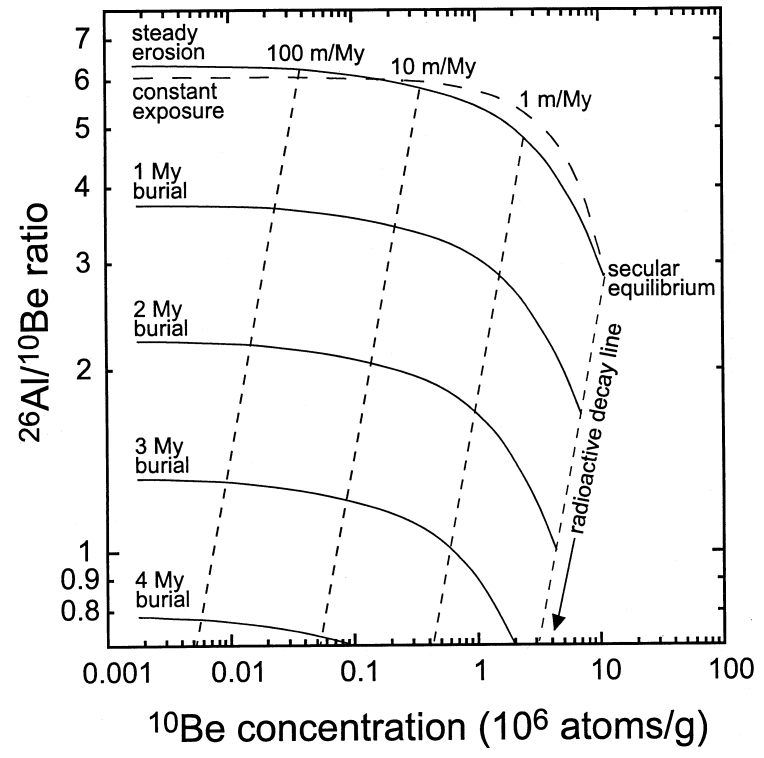

Fig. 1. Burial dating plot showing the ${ }^{26} \mathrm{Al} /{ }^{10} \mathrm{Be}$ ratio and ${ }^{10} \mathrm{Be}$ concentration in sediment. Production parameters from the text were used to create the plot, which includes the effects of muonic production. Quartz grains with no burial history should plot between the 'constant exposure' and 'steady erosion' lines defined by Eqs. 9 and 10 and Eqs. 21 and 22 in the text [7]. Note that muonic production causes these two lines to cross. For sediment that is buried and completely shielded from cosmic rays, the ${ }^{26} \mathrm{Al} /{ }^{10} \mathrm{Be}$ ratio decreases along a line parallel to the dashed 'radioactive decay line'. Million-year isochrons are shown for sediment burial following steady erosion.

value given by:

$\frac{N_{\mathrm{Al}}(0)}{N_{\mathrm{Be}}(0)}=P_{\mathrm{Al}}\left(P_{\mathrm{Be}}+N_{\mathrm{Be}}(0)\left(\frac{1}{\tau_{\mathrm{Al}}}-\frac{1}{\tau_{\mathrm{Be}}}\right)\right)^{-1}$

This curve forms the upper limit to all possible data points. The set of possible data points is bounded on the right by the zero-erosion curve that plots radioactive decay from a condition of secular equilibrium [6]:

$$
\begin{aligned}
& \left(\frac{N_{\mathrm{Al}}(t)}{N_{\mathrm{Be}}(t)}\right)_{E=0}= \\
& \quad P_{\mathrm{Al}} \tau_{\mathrm{Al}}\left(P_{\mathrm{Be}} \tau_{\mathrm{Be}}\right)^{-\tau_{\mathrm{Be}} / \tau_{\mathrm{Al}}}\left(N_{\mathrm{Be}}(t)\right)^{\tau_{\mathrm{Be}} / \tau_{\text {burial }}}
\end{aligned}
$$

\subsection{Other preburial models}

In Section 3.2 we treated the case in which the quartz is derived from an eroding landform, and assumed that the depth dependence of the cosmogenic nuclide production followed simple exponential laws (Eq. 11). This led to Eqs. 12 and 13 for the initial concentrations. In some situations the more complete equations presented in Section 2 must be used:

$$
\begin{aligned}
& P_{\mathrm{Al}}(z)=A_{0} \mathrm{e}^{-z / L_{0}}+A_{1} \mathrm{e}^{-z / L_{1}}+A_{2} \mathrm{e}^{-z / L_{2}}+A_{3} \mathrm{e}^{-z / L_{3}} \\
& P_{\mathrm{Be}}(z)=B_{0} \mathrm{e}^{-z / L_{0}}+B_{1} \mathrm{e}^{-z / L_{1}}+B_{2} \mathrm{e}^{-z / L_{2}}+B_{3} \mathrm{e}^{-z / L_{3}}
\end{aligned}
$$

This leads to the following equations for the initial concentrations when the quartz is part of an eroding landform:

$$
\begin{aligned}
& N_{\mathrm{Al}}(0)= \\
& \quad \frac{A_{0}}{\frac{1}{\tau_{\mathrm{Al}}}+\frac{E}{L_{0}}}+\frac{A_{1}}{\frac{1}{\tau_{\mathrm{Al}}}+\frac{E}{L_{1}}}+\frac{A_{2}}{\frac{1}{\tau_{\mathrm{Al}}}+\frac{E}{L_{2}}}+\frac{A_{3}}{\frac{1}{\tau_{\mathrm{Al}}}+\frac{E}{L_{3}}}
\end{aligned}
$$

$N_{\text {Be }}(0)=$

$$
\frac{B_{0}}{\frac{1}{\tau_{\mathrm{Be}}}+\frac{E}{L_{0}}}+\frac{B_{1}}{\frac{1}{\tau_{\mathrm{Be}}}+\frac{E}{L_{1}}}+\frac{B_{2}}{\frac{1}{\tau_{\mathrm{Be}}}+\frac{E}{L_{2}}}+\frac{B_{3}}{\frac{1}{\tau_{\mathrm{Be}}}+\frac{E}{L_{3}}}
$$

We can then combine these two equations with Eq. 4 to get two simultaneous equations for two unknowns ( $t$ and $E$ ):

$$
\begin{gathered}
N_{\mathrm{Al}}(t)=\left(\frac{A_{0}}{\frac{1}{\tau_{\mathrm{Al}}}+\frac{E}{L_{0}}}+\frac{A_{1}}{\frac{1}{\tau_{\mathrm{Al}}}+\frac{E}{L_{1}}}+\right. \\
\left.\frac{A_{2}}{\frac{1}{\tau_{\mathrm{Al}}}+\frac{E}{L_{2}}}+\frac{A_{3}}{\frac{1}{\tau_{\mathrm{Al}}}+\frac{E}{L_{3}}}\right) \mathrm{e}^{-t / \tau_{\mathrm{Al}}}
\end{gathered}
$$




$$
\begin{gathered}
N_{\mathrm{Be}}(t)=\left(\frac{B_{0}}{\frac{1}{\tau_{\mathrm{Be}}}+\frac{E}{L_{0}}}+\frac{B_{1}}{\frac{1}{\tau_{\mathrm{Be}}}+\frac{E}{L_{1}}}+\right. \\
\left.\frac{B_{2}}{\frac{1}{\tau_{\mathrm{Be}}}+\frac{E}{L_{2}}}+\frac{B_{3}}{\frac{1}{\tau_{\mathrm{Be}}}+\frac{E}{L_{3}}}\right) \mathrm{e}^{-t / \tau_{\mathrm{Be}}}
\end{gathered}
$$

Of course, these are just more complicated versions of Eqs. 14 and 15. Measurement of the nuclide concentrations $N_{\mathrm{Al}}(t)$ and $N_{\mathrm{Be}}(t)$ allows us to determine the burial age $t$. The graphical solution to these equations is shown in Fig. 1.

When the erosion rate is low enough, only the first terms in Eqs. 21 and 22 are important and the simpler equations (Eqs. 12 and 13) may be used. Any cosmogenic nuclides produced by muons at great depth will decay before the quartz reaches the surface. This occurs when $E \ll L_{1} / \tau_{\mathrm{Be}}$, or when the erosion rate is less than about 0.001 $\mathrm{mm} / \mathrm{yr}$.

In the opposite limit, when the erosion rate is very high:

$$
\begin{aligned}
& N_{\mathrm{Al}}(0) \approx \frac{1}{E}\left(A_{0} L_{0}+A_{1} L_{1}+A_{2} L_{2}+A_{3} L_{3}\right) \\
& N_{\mathrm{Be}}(0) \approx \frac{1}{E}\left(B_{0} L_{0}+B_{1} L_{1}+B_{2} L_{2}+B_{3} L_{3}\right)
\end{aligned}
$$

In this high erosion limit, the last three terms make non-negligible contributions. For example, the last term in Eq. 25, due to fast muons, is $15 \%$ of the first term. This occurs when $E \gg L_{3} / \tau_{\mathrm{Be}}$, or when the erosion rate is much greater than 0.01 $\mathrm{mm} / \mathrm{yr}$.

\subsection{Complicated exposure histories}

We have considered models in which the sediment source has been eroding at a constant rate for a long period of time. For many landscapes this situation may not hold. Even so, accounting for variable erosion rates seldom affects burial dates significantly. As long as erosion rates are sufficiently rapid that radioactive decay may be ignored (i.e. $E \gg 0.6 \mathrm{~m} / \mathrm{Myr}$ ) the initial ${ }^{26} \mathrm{Al} /{ }^{10} \mathrm{Be}$ ratio is unaffected by even large variations in erosion rate. Even in slowly eroding landscapes such as Australia [28,29], southern Africa [30], and the central US [11], measured ${ }^{26} \mathrm{Al} /{ }^{10} \mathrm{Be}$ ratios in sediment fall near their expected steady-state values. Exceptions arise in situations where sediment is repeatedly buried for long periods of time, such as in migrating sand dunes [6] or beneath ice sheets [8]. ${ }^{26} \mathrm{Al} /{ }^{10} \mathrm{Be}$ ratios may also be lowered where erosion occurs by spalling large sheets of bedrock $[15,30]$. Where sediment may have been derived from areas with complicated preburial exposure histories, cosmogenic burial dates should be considered maximum ages.

\section{Postburial nuclide production}

In Section 3 we considered the most straightforward case of burial dating, in which production of cosmogenic nuclides completely stops at the time of burial. In this section we will discuss situations in which production does not completely cease upon burial.

\subsection{Burial at constant depth}

Suppose that quartz was buried at time $t=0$ at depth $z=d$, with inherited nuclide concentrations $N_{\mathrm{Al}}(0)$ and $N_{\mathrm{Be}}(0)$. However, in contrast to Section 3, cosmogenic nuclide production continues because the quartz is not buried deeply enough to completely shield the cosmic radiation. Thus, the nuclide concentrations are given by (we assume that the depth remains constant at $z=d)$ :

$$
N_{\mathrm{Al}}(t)=N_{\mathrm{Al}}(0) \mathrm{e}^{-t / \tau_{\mathrm{Al}}}+P_{\mathrm{Al}}(d) \tau_{\mathrm{Al}}\left(1-\mathrm{e}^{-t / \tau_{\mathrm{Al}}}\right)
$$

$$
N_{\mathrm{Be}}(t)=N_{\mathrm{Be}}(0) \mathrm{e}^{-t / \tau_{\mathrm{Be}}}+P_{\mathrm{Be}}(d) \tau_{\mathrm{Be}}\left(1-\mathrm{e}^{-t / \tau_{\mathrm{Be}}}\right)
$$

Eqs. 27 and 28 are a set of two equations for two unknowns, where one of the unknowns is the burial time $t$. The other unknown is either $T$ (if we use Eq. 5 to describe the initial concentrations) or $E$ (if we use Eqs. 12 and 13 or Eqs. 21 and 22). 
The importance of postburial production in determining an accurate burial age is governed by several factors:

1. For a fixed $t$ the longer the preburial exposure, the smaller the effects of postburial production will be. One should realize, however, that no matter how long this preburial exposure lasts, the initial concentrations are bounded above by their saturation values, given by Eq. 35 .

2. For fixed values of the initial concentrations, the longer the burial period, the more important postburial production becomes.

3. The deeper the burial, the less important postburial production becomes.

In Eqs. 27 and 28 the first term is decreasing as time goes on, while the second term, representing the postburial production, is increasing. The time at which the second term equals a fraction $\beta$ of the first term, with perhaps $\beta=0.2$, gives a rough estimate of the time at which postburial production becomes significant. Solving for this time for ${ }^{26} \mathrm{Al}$ gives:

$t^{*}=\tau_{\mathrm{Al}} \ln \left(1+\frac{\beta N_{\mathrm{Al}}(0)}{P_{\mathrm{Al}}(d) \tau_{\mathrm{Al}}}\right)$

For burial times much shorter than $t^{*}$ postburial production can be safely ignored, while for times comparable to or longer than $t^{*}$, calculation of the burial time will be seriously in error if postburial production is ignored. Fig. 2 displays plots of $t^{*}$ as a function of burial depth for several choices of initial nuclide concentrations.

The magnitude of the postburial production effects can be illustrated in another way. Suppose, for a given set of data (i.e. $N_{\mathrm{Al}}(t), N_{\mathrm{Be}}(t)$ ) we solve Eqs. 27 and 28 for the two unknowns $(t, T)$, using Eq. 5 to model the initial concentrations. We can solve for $(t, T)$ using the complete equations to get the true burial age; we can also solve for $(t, T)$ by ignoring the second terms in Eqs. 27 and 28, thus computing a burial age $t_{\text {naive }}$ which ignores postburial production. Fig. 3 shows a plot of the naive age versus the true burial age, for several choices of $T$. For shorter values of $t$, and longer values of $T$, the value of $t_{\text {naive }}$ is not far off. As the burial time increases, however, the incorrect calculation becomes more and more unsatisfactory.

An example of the importance of muons for shallowly buried samples can be seen in an abstract presented by Granger and Smith [31], who ignored muon production when interpreting ${ }^{26} \mathrm{Al}$ and ${ }^{10} \mathrm{Be}$ in sediments buried at a depth of about $10 \mathrm{~m}$ in an abandoned river channel. They incorrectly inferred that the samples had been buried for $1.13 \pm 0.16 \mathrm{Myr}$. Later analyses of the same data included postburial production by muons, and the burial age was then inferred to be $1.50 \pm 0.30$ Myr [32].

\subsection{Burial at time-dependent depth}

In the previous subsection we assumed that a quartz clast was buried at time $t=0$ at a constant depth $z=d$. We now discuss three different ways to analyze a situation in which the postburial

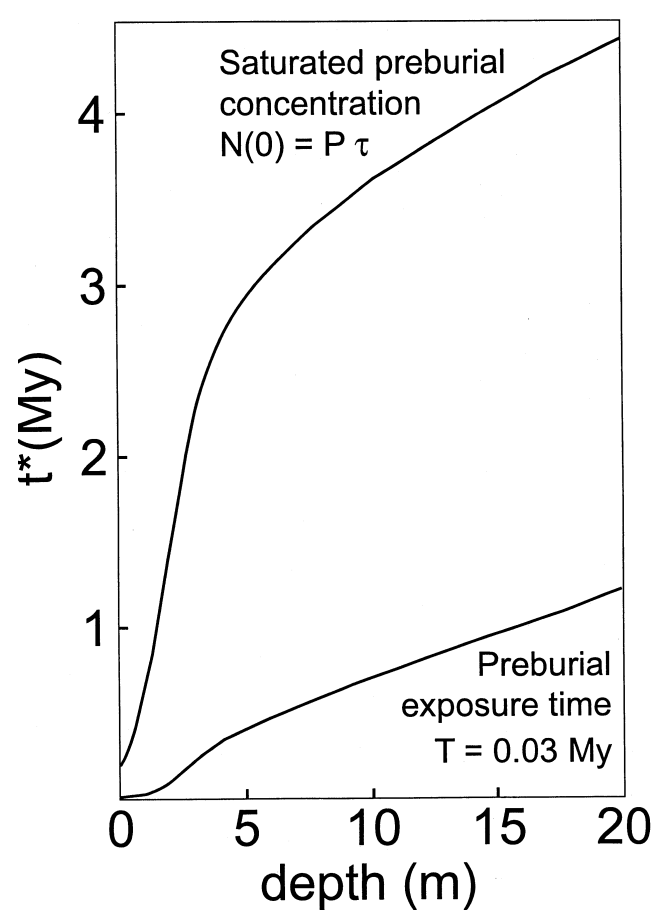

Fig. 2. This figure shows a plot of $t^{*}$ as a function of depth. Eq. 29 is used to compute $t^{*}$, with $\beta=0.2$. The lower curve has $N_{\mathrm{Al}}(0)=P_{\mathrm{Al}} \mathrm{T}$, with $T=0.03 \mathrm{Myr}$, while the upper curve has $N_{\mathrm{Al}}(0)=P_{\mathrm{Al}} \tau_{\mathrm{Al}}$, its saturation value. $t^{*}$ is an estimate of the timescale, for a given depth, at which muons seriously affect the burial dating method. 


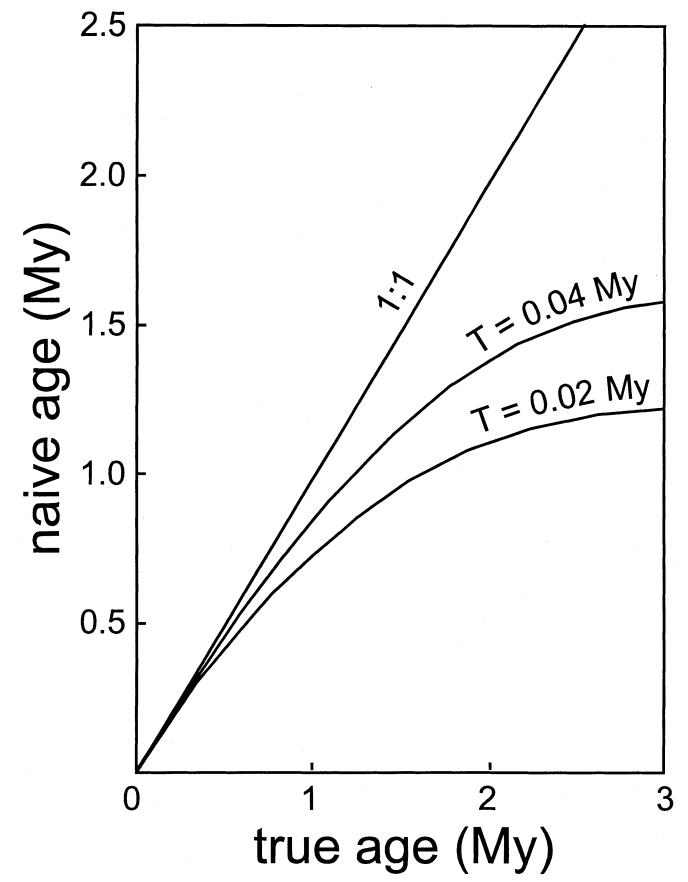

Fig. 3. Plot of the naive burial age versus the true burial age. As discussed in Section 4, the true age is computed by solving Eqs. 27 and 28, with the initial concentrations given by Eq. 5 ; the naive age is computed by ignoring the muonic production effects in these equations. The lower curve has $T=0.02 \mathrm{Myr}$, while the middle curve has $T=0.04 \mathrm{Myr}$; both curves have a depth equal to $10 \mathrm{~m}$. The straight line gives the line on which the naive age equals the true age.

depth is not constant. This depth may vary with time because of erosion, or because more material is later deposited on the surface.

\subsubsection{Subtracting postburial production}

If postburial production can be accounted for and subtracted from the data then the methods of Section 3 can be applied to the corrected ${ }^{26} \mathrm{Al}$ and ${ }^{10} \mathrm{Be}$ concentrations. For example this subtraction procedure could work on a strath terrace where sediment is deposited on quartz-bearing bedrock. In this scenario, the sediment contains inherited concentrations of cosmogenic nuclides, while the bedrock initially contains no cosmogenic nuclides. After burial both the bedrock surface and the sediment are exposed to the same cosmic rays for the same period of time at the same burial depth, and so have the same postburial cosmo- genic nuclide production. Concentrations in the bedrock quartz can then be subtracted from the concentrations in the sediment quartz to determine the remaining quantities of inherited nuclides in the sediment.

\subsubsection{Depth profile method}

Suppose at time $t=0$ a layer of sediment of thickness $D$ containing quartz clasts is deposited, and immediately buried under a layer of overburden. The quartz throughout the sediment layer is taken to have initial concentrations of $N_{\mathrm{Al}}(0)$ and $N_{\mathrm{Be}}(0)$. If the sediment layer remains of thickness $D$, but its depth varies with time, then at a later time $t$ (i.e. now) the nuclide concentrations within the sediment layer are given by:

$$
\begin{aligned}
& N_{\mathrm{Al}}(z, t)=N_{\mathrm{Al}}(0) \mathrm{e}^{-t / \tau_{\mathrm{Al}}}+\sum_{j=0}^{3} Q_{j} \mathrm{e}^{-z / L_{j}} \\
& N_{\mathrm{Be}}(z, t)=N_{\mathrm{Be}}(0) \mathrm{e}^{-t / \tau_{\mathrm{Be}}}+\sum_{j=0}^{3} S_{j} \mathrm{e}^{-z / L_{j}}
\end{aligned}
$$

The coefficients $Q_{j}$ and $S_{j}$ depend on the burial time $t$, but are independent of the present depth $z$. Note that in deriving these equations it is not necessary to assume a constant erosion rate.

One possible strategy for determining the burial age $t$ is to collect samples at various depths $z$, and measure the nuclide concentrations in the quartz. We can then fit this $z$-dependent data to Eqs. 30 and 31 , thereby obtaining values for the coefficients $Q_{j}$ and $S_{j}$, and for the initial $z$-independent terms. Using this fit, we then obtain the following two equations:

$F_{\mathrm{Al}}=N_{\mathrm{Al}}(0) \mathrm{e}^{-t / \tau_{\mathrm{Al}}} ; F_{\mathrm{Be}}=N_{\mathrm{Be}}(0) \mathrm{e}^{-t / \tau_{\mathrm{Be}}}$

where the values of $F_{\mathrm{Al}}$ and $F_{\mathrm{Be}}$ are concentrations that come from the fit of the data. The initial concentrations may then be modeled by any of the methods given in Section 3 to determine the burial age $t$.

The strategy described above has a major weakness. Unless data can be collected from a wide enough range of depths, fitting the data to Eqs. 30 and 31 does not produce a well-constrained set 
of values for the unknown coefficients. In particular, the leading $z$-independent terms will not be determined with good precision.

\subsubsection{Depth profile with constant erosion rate}

The strategy presented in Section 4.2.2 has the advantage of not assuming a constant erosion rate in the determination of the burial age; however, it can suffer from a poorly constrained fit and thus a poorly determined age. One way to remedy this is to assume that after burial (at time $t=0$ ) the sediment layer of thickness $D$ is exhumed at a constant erosion rate $E_{\mathrm{p}}$ [10]. (The subscript 'p' indicates postburial erosion rate, in contrast to the inherited erosion rate $E$ which appears in Section 3.) With this assumption, the values for the coefficients $S_{j}$ and $Q_{j}$ are given by:

$$
\begin{gathered}
Q_{j}=A_{j} \frac{\left(1-\mathrm{e}^{-\left(1 / \tau_{\mathrm{Al}}+E_{\mathrm{p}} / L_{j}\right) t}\right)}{1 / \tau_{\mathrm{Al}}+E_{\mathrm{p}} / L_{j}} \\
S_{j}=B_{j} \frac{\left(1-\mathrm{e}^{-\left(1 / \tau_{\mathrm{Be}}+E_{\mathrm{p}} / L_{j}\right) t}\right)}{1 / \tau_{\mathrm{Be}}+E_{\mathrm{p}} / L_{j}}
\end{gathered}
$$

Eqs. 30 and 31 may then be fit to the data with only three unknowns $\left(t, E\right.$, and $\left.E_{\mathrm{p}}\right)$ which can be accurately determined.

\section{Age range of burial dating}

The effective range of burial dating depends on the nuclides being used. For ${ }^{26} \mathrm{Al}$ and ${ }^{10} \mathrm{Be}$ in quartz the lower limit of the method is of order $100 \mathrm{kyr}$; this value is essentially a matter of experimental error.

Recall from Section 3.1 that an uncertainty of $5 \%$ in the ${ }^{26} \mathrm{Al} /{ }^{10} \mathrm{Be}$ ratio led to an uncertainty in age of $96 \mathrm{kyr}$. The ${ }^{26} \mathrm{Al} /{ }^{10} \mathrm{Be}$ ratio is determined by measuring ${ }^{26} \mathrm{Al} /{ }^{27} \mathrm{Al}$ and ${ }^{10} \mathrm{Be} /{ }^{9} \mathrm{Be}$ with $\mathrm{AMS}$, and by using chemical methods to determine the concentrations of the stable isotopes ${ }^{27} \mathrm{Al}$ and ${ }^{9} \mathrm{Be}$. The AMS measurements of these two isotope ratios are typically limited to a precision of $3 \%$, and so the uncertainty due to the AMS measurements is at least $4-5 \%$. The chemistry will introduce additional uncertainty.

In addition to the errors in measuring $R$, there are systematic uncertainties. The production rates are not known to better than several percent, and they also vary with time. The mean lives for ${ }^{26} \mathrm{Al}$ and ${ }^{10} \mathrm{Be}$ are also known only to within several percent. When we take into account all of the above sources of error, we can see that achieving uncertainties below about $100 \mathrm{kyr}$ will pose a severe challenge.

The upper limit of the age range for burial dating is of order $5 \mathrm{Myr}$. Several factors help in setting this limit. One obvious point is that as the burial time increases, the decreasing amounts of ${ }^{10} \mathrm{Be}$ and ${ }^{26} \mathrm{Al}$ in the quartz become difficult to measure. At present the detection limits for the ratios ${ }^{26} \mathrm{Al} /{ }^{27} \mathrm{Al}$ and ${ }^{10} \mathrm{Be} /{ }^{9} \mathrm{Be}$ are of order $10^{-15}$ [2]. Note that there is an upper limit to the concentrations present at burial:

$N_{\mathrm{Be}}(0) \leq P_{\mathrm{Be}} \tau_{\mathrm{Be}} ; N_{\mathrm{Al}}(0) \leq P_{\mathrm{Al}} \tau_{\mathrm{Al}}$

where the production rates in these equations are the surface values.

These values will seldom be reached in actual samples. In fact, samples may often be buried with very low cosmogenic nuclide concentrations, in which case the practical upper limit to the burial dating technique may be less than $5 \mathrm{Myr}$. It is important to note that the absence of cosmogenic nuclides in a buried clast can result from either a long burial time or a short preburial exposure. It is not possible to distinguish these possibilities without additional information.

Another reason for the upper age limit, for burial depths less than about $30 \mathrm{~m}$, is that nuclide production continues after burial, mainly due to muons. The methodology of burial dating is based on the decrease with time of the nuclide concentrations. After enough time has passed, radioactive decay will be balanced by production and this decrease will stop. The time at which postburial production essentially destroys the method's effectiveness can be estimated from Eq. 29. To obtain the largest, most optimistic value for this estimate, we may use Eq. 35 for the initial concentrations. We see that, even for burial at depths ranging up to $30 \mathrm{~m}$, the logarithm in Eq. 29 can at most evaluate to about 5, giving an effective range $t^{*}$ of order $5 \mathrm{Myr}$. 


\section{Discussion}

\subsection{Other cosmogenic nuclides}

We have discussed burial dating using ${ }^{26} \mathrm{Al}$ and ${ }^{10} \mathrm{Be}$ in quartz. This pair of nuclides is particularly attractive for burial dating. Although the production rates for these isotopes are affected by latitude, altitude, and depth, the rates for the two isotopes are affected in the same way; their ratio is largely independent of these factors. Other cosmogenic nuclide pairs may not have this convenient feature.

We now discuss other cosmogenic nuclides which have potential use in burial dating. ${ }^{36} \mathrm{Cl}$ has a mean life of $\tau_{\mathrm{Cl}}=0.444 \mathrm{Myr}$ and is produced primarily in rocks containing $\mathrm{Cl}, \mathrm{K}$, and $\mathrm{Ca}$. If this nuclide is paired with ${ }^{10} \mathrm{Be}$, then $\tau_{\text {burial }}=0.56$ Myr; recall that $\tau_{\text {burial }}$ was defined in Section 3, and is the characteristic decay time for the nuclide ratio $R$. Thus, this pair of nuclides could be used for somewhat shorter burial times than the ${ }^{26} \mathrm{Al}-$ ${ }^{10} \mathrm{Be}$ pair, and would have an uncertainty in burial age of about $30 \mathrm{kyr}$.

A difficulty in using the ${ }^{36} \mathrm{Cl}-{ }^{10} \mathrm{Be}$ pair is that their relative production rates can vary over a wide range, because ${ }^{36} \mathrm{Cl}$ production is composition-dependent. In addition, ${ }^{36} \mathrm{Cl}$ is also produced by thermal neutron capture, which has a different depth dependence than nuclear spallation [19]. Thus, the ${ }^{36} \mathrm{Cl}-{ }^{10} \mathrm{Be}$ pair should be used with caution, and only in rocks where the inherited ratio of ${ }^{36} \mathrm{Cl}$ to ${ }^{10} \mathrm{Be}$ can be reliably estimated.

Another candidate for burial dating is ${ }^{14} \mathrm{C}$ in quartz. Its mean life is $\tau_{\mathrm{C}}=8267 \mathrm{yr}$, which, if combined with ${ }^{10} \mathrm{Be}$ gives a value of $\tau_{\text {burial }}=8298$ yr. Thus, the ${ }^{14} \mathrm{C}-{ }^{10} \mathrm{Be}$ pair could be used to measure burial times of order thousands to tens of thousands of years. However, the fast decay of ${ }^{14} \mathrm{C}$ suggests that most slowly eroding rocks may have ${ }^{14} \mathrm{C}$ concentrations near secular equilibrium (i.e. $N_{\mathrm{C}}(0)=P_{\mathrm{C}} \tau_{\mathrm{C}}$ ). The initial ratio of ${ }^{14} \mathrm{C}$ to longer-lived radionuclides may then vary over a wide range. One possible simplifying feature in using ${ }^{14} \mathrm{C}$ is that its inherited concentration could be assumed to be equal to its secular equilibrium value; then, ${ }^{14} \mathrm{C}$ could be used alone for burial dating, with no need for another nuclide.
Finally, stable cosmogenic nuclides such as ${ }^{3} \mathrm{He}$ and ${ }^{21} \mathrm{Ne}$ can potentially be used in tandem with unstable nuclides to date sediment burial. The stable nuclide would be used to infer the preburial exposure history, which would allow one to determine the initial concentration of the unstable nuclide and the burial age. The primary difficulty with stable nuclides is that their concentrations depend on the long term exposure history of the rock, while radionuclides record a rock's exposure or erosion history only over the timescale of radioactive decay. Stable nuclides must therefore be used with caution.

\subsection{Directions for future research}

One important goal of future research is to improve the accuracy and precision of burial dating. At present, accuracy is not usually limited by the precision of AMS measurements but by uncertainties in production rates and decay times. It is particularly important to understand the production rates of the various cosmogenic nuclides. Careful measurements should be made of cosmogenic nuclide production rates with depth in wellconstrained geological sites, at a variety of latitudes and altitudes, to fully understand how production rates vary at depths of up to $30 \mathrm{~m}$ $[23,24,33]$.

Finally, methods should be developed for using three cosmogenic nuclides in a single rock or sediment sample. Provided that production of all three nuclides follows the same behavior with depth, measurement of three concentrations overconstrains the equations presented in this paper. Addition of the third measurement would permit a test of the constant exposure or steady erosion assumptions, and would confirm that sediment has been buried only once. Developments such as these would improve the confidence with which burial dating could be applied in a wide variety of geologic environments.

\section{Acknowledgements}

D.E.G. was supported by NSF Grant EAR- 
9706011. We thank D. Lal and J. Gosse for reviews that improved this paper.[RV]

\section{References}

[1] D. Lal, B. Peters, Cosmic ray produced radioactivity on the Earth, in: S. Flugge (Ed.), Handbuch der Physik, vol. 46, Springer, Berlin, 1967, pp. 551-612.

[2] C. Tuniz, J.R. Bird, D. Fink, G.F. Herzog, Accelerator Mass Spectrometry: Ultrasensitive Analysis for Global Science, CRC Press, Boca Raton, FL, 1998.

[3] K. Nishiizumi, E.L. Winterer, C.P. Kohl, J. Klein, R. Middleton, D. Lal, J.R. Arnold, Cosmic ray production rates of ${ }^{10} \mathrm{Be}$ and ${ }^{26} \mathrm{Al}$ in quartz from glacially polished rocks, J. Geophys. Res. 94 (1989) 17907-17915.

[4] E.T. Brown, E.J. Brook, G.M. Raisbeck, F. Yiou, M.D. Kurz, Effective attenuation lengths of cosmic producing ${ }^{10} \mathrm{Be}$ and ${ }^{26} \mathrm{Al}$ in quartz, implications for exposure age dating, Geophys. Res. Lett. 19 (1992) 369-372.

[5] D. Lal, J.R. Arnold, Tracing quartz through the environment, Proc. Indian Acad. Sci. Earth Planet. Sci. 94 (1985) $1-5$.

[6] J. Klein, R. Giegengack, R. Middleton, P. Sharma, J.R.J. Underwood, R.A. Weeks, Revealing histories of exposure using in situ produced ${ }^{26} \mathrm{Al}$ and ${ }^{10} \mathrm{Be}$ in Libyan desert glass, Radiocarbon 28 (1986) 547-555.

[7] D. Lal, Cosmic ray labeling of erosion surfaces: in situ nuclide production rates and erosion models, Earth Planet. Sci. Lett. 104 (1991) 424-439.

[8] P.R. Bierman, K.A. Marsella, C. Patterson, P.T. Davis, M. Caffee, Mid-Pleistocene cosmogenic minimum-age limits for pre-Wisconsinan glacial surfaces in southwestern Minnesota and southern Baffin Island: a multiple nuclide approach, Geomorphology 27 (1999) 25-39.

[9] D.E. Granger, J.W. Kirchner, R.C. Finkel, Quaternary downcutting rate of the New River, Virginia, measured from differential decay of cosmogenic ${ }^{26} \mathrm{Al}$ and ${ }^{10} \mathrm{Be}$ in cave-deposited alluvium, Geology 25 (1997) 107-110.

[10] D.E. Granger, A.L. Smith, Dating buried sediments using radioactive decay and muogenic production of ${ }^{26} \mathrm{Al}$ and ${ }^{10}$ Be, Nucl. Instrum. Methods Phys. Res. B 172 (2000) $822-826$.

[11] D.E. Granger, D. Fabel, A.N. Palmer, Pliocene-Pleistocene incision of the Green River, Kentucky, determined from radioactive decay of cosmogenic ${ }^{26} \mathrm{Al}$ and ${ }^{10} \mathrm{Be}$ in Mammoth Cave sediments, Geol. Soc. Am. Bull. (2001), in press.

[12] T.E. Cerling, H. Craig, Geomorphology and in-situ cosmogenic isotopes, Annu. Rev. Earth Planet. Sci. 22 (1994) 273-317.

[13] P.R. Bierman, Using in-situ produced cosmogenic isotopes to estimate rates of landscape evolution: a review from the geomorphic perspective, J. Geophys. Res. 99 (1994) 13885-13896.

[14] K. Nishiizumi, C.P. Kohl, J.R. Arnold, R. Dorn, J. Klein,
D. Fink, R. Middleton, D. Lal, Role of in-situ cosmogenic nuclides ${ }^{10} \mathrm{Be}$ and ${ }^{26} \mathrm{Al}$ in the study of diverse geomorphic processes, Earth Surf. Process. Landf. 18 (1993) 407425.

[15] J.C. Gosse, F.M. Phillips, Terrestrial cosmogenic nuclides: theory and applications, Quat. Sci. Rev. 20 (2001).

[16] J.C. Gosse, J. Klein, E.B. Evenson, B. Lawn, R. Middleton, Beryllium-10 dating of the duration and retreat of the last Pinedale glacial sequence, Science 268 (1995) 13291333.

[17] J. Leland, M.R. Reid, D.W. Burbank, R. Finkel, M. Caffee, Incision and differential bedrock uplift along the Indus River near Nanga parbat, Pakistan Himalaya, from ${ }^{10} \mathrm{Be}$ and ${ }^{26} \mathrm{Al}$ exposure age dating of bedrock straths, Earth Planet. Sci. Lett. 154 (1998) 93-107.

[18] P.W. Kubik, S. Ivy-Ochs, J. Masarik, M. Frank, C. Schlüchter, ${ }^{10} \mathrm{Be}$ and ${ }^{26} \mathrm{Al}$ production rates deduced from an instantaneous event within the dendro-calibration curve, the landslide of Köfels, Ötz Valley, Austria, Earth Planet. Sci. Lett. 161 (1998) 231-241.

[19] R.C. Reedy, K. Nishiizumi, D. Lal, J.R. Arnold, P.A.J. Englert, J. Klein, R. Middleton, A.J.T. Jull, D.J. Donahue, Simulations of terrestrial in-situ cosmogenic nuclide production, Nucl. Instrum. Methods Phys. Res. B 92 (1994) 297-300.

[20] T.J. Dunai, Scaling factors for production rates of in-situ produced cosmogenic nuclides: a critical reevaluation, Earth Planet. Sci. Lett. 176 (2000) 157-169.

[21] J.C. Gosse, J.O. Stone, Terrestrial cosmogenic nuclide methods passing milestones toward paleo-altimetry, EOS Trans. Am. Geophys. Union 82 (2001) 82-89.

[22] E.T. Brown, D.L. Bourles, F. Colin, G.M. Raisbeck, F. Yiou, S. Desgarceaux, Evidence for muon-induced in-situ production of ${ }^{10} \mathrm{Be}$ in near-surface rocks from the Congo, Geophys. Res. Lett. 22 (1995) 703-706.

[23] J.O.H. Stone, J.M. Evans, L.K. Fifield, G.L. Allan, R.G. Cresswell, Cosmogenic chlorine-36 production in calcite by muons, Geochim. Cosmochim. Acta 62 (1998) 433454.

[24] B.P. Heisinger, Myonen-induzierte produktion von radionukliden, Ph.D. thesis, Technischen Universität Munich, 1998.

[25] H. Bilokon, G.C. Castagnoli, A. Castellina, B.D.E. Piazzoli, G. Mannocchi, E. Meroni, P. Picchi, S. Vernetto, Flux of the vertical negative muons stopping at depths 0.35-1000 hg/cm², J. Geophys. Res. 94 (1989) 12145 12152 .

[26] T.L. Norris, A.J. Gancarz, D.J. Rokop, K.W. Thomas, Half-life of ${ }^{26} \mathrm{Al}$, Proceedings of the 14th Lunar and Planetary Science Conference, Part I, J. Geophys. Res. 88 (1983) B331-B333.

[27] H.J. Hofmann, J. Beer, G. Bonani, H.R. Von Gunten, S. Raman, M. Suter, R.L. Walker, W. Wolfli, D. Zimmerman, ${ }^{10} \mathrm{Be}$ : half-life and AMS-standards, Nucl. Instrum. Methods Phys. Res. B 29 (1987) 32-36.

[28] P.R. Bierman, J. Turner, ${ }^{10} \mathrm{Be}$ and ${ }^{26} \mathrm{Al}$ evidence for exceptionally low rates of Australian bedrock erosion and 
the likely existence of pre-Pleistocene landscapes, Quat. Res. 44 (1995) 378-382.

[29] A.M. Heimsath, J. Chappell, W.E. Dietrich, K. Nishiizumi, R.C. Finkel, Soil production on a retreating escarpment in southeastern Australia, Geology 28 (2000) 787790.

[30] H.A.P. Cockburn, R.W. Brown, M.A. Summerfield, M.A. Seidl, Quantifying passive margin denudation and landscape development using a combined fission-track thermochronology and cosmogenic isotope analysis approach, Earth Planet. Sci. Lett. 179 (2000) 429-435.

[31] D.E. Granger, A.L. Smith, Early Laurentide glaciation and creation of the Ohio River dated by radioactive decay of cosmogenic Al-26 and Be-10 in proglacial sediments, GSA Abstr. Programs 30 (1998) A298.

[32] D.E. Granger, A.L. Smith, Glacial origin of the Ohio River dated by radioactive decay of cosmogenic ${ }^{26} \mathrm{Al}$ and ${ }^{10} \mathrm{Be}$ in proglacial sediments, Quat. Res. (2001), submitted for publication.

[33] E. Strack, B. Heisinger, B. Dockhorn, F.J. Hartmann, G. Korschinek, E. Nolte, G. Morteani, C. Petitjean, S. Neumaier, Determination of erosion rates with cosmogenic ${ }^{26} \mathrm{Al}$, Nucl. Instrum. Methods Phys. Res. B 92 (1994) 317-320. 